\title{
The infrared thermography of buildings proceeding its surrounding and their thermal performance.
}

by J. Jaworski

\begin{abstract}
In carrying out the thermographical research of buildings, including the conditions to conduct this thermal imagining of buildings, one must take into account a rather small rank of temperature differences between outer surfaces of buildings and their surroundings. This is particularly vital if one compares other types and methods for carrying our thermography survey. In this connection, for the thermographical researches of buildings and defining the conditions for such research, it appears that the key issue is the equilibrium of the heat radiation, at the surveyed surface. Quantitative building thermography is radiometric imaging method to determinate values like overall heat transfer coefficient of $U$ and thermal building performance $\eta$ - efficiency, or the heat permeability $\tilde{\theta}$ from the buildings. All above values were inter-connected by the coefficient heat transfer $h_{\circ}$ at a wall surface of the surveyed building envelope.
\end{abstract}

\section{Introduction}

The analysis method of heat dissipated from buildings to surroundings basing on remote radiometric measurement of thermal radiation is important method of buildings quality control regarding the quantity of energy supplied for heating it. Significance of the method raises during energy price increase as well the rate of energy demand. This paper presents findings of research work on use of infrared thermography [5] to quantitative evaluation of heat loses from buildings to their surroundings and to evaluate their thermal efficiency.

\section{The buildings wall overall heat transfer coefficient $U$ determination.}

Processes of heat transfer and water transport through lining components from indoor air to outdoor one or to the soil take place in the components of building envelope. This transfer covers the thermal conduction in the air and in lining materials, heat convection connected with air movement at the lining boundary and movement of water and its phase transition. Building components cooling or heating process also comes from differences in direct thermal radiation or dissipated radiation, in short- and long-wave range, during day and night in the summer or winter as well as sky overcast. Here the following is present: absorption of short-wave thermal radiation which is the Sun irradiance and emission which is the long-wave thermal emittance of building components.

Heat transfer is described and determined by the term called thermal flux. It means that the heat quantity assigned in time unit. Temperature difference is causing thermal flux. Thermal flux is some function of temperature difference $(\Delta \mathrm{T})$.

$$
\Phi=\mathrm{f}(\Delta \mathrm{T})
$$
difference.

At the same time it's commonly accepted that thermal flux density is linear function of temperature

where:

$$
q=\Phi / A=\beta . \Delta T
$$

$\Phi$ - is the heat-energy flux [J/s] $=[\mathrm{W}]$,

$\mathrm{A}$ - is the (control) area of flux under consideration $\left[\mathrm{m}^{2}\right]$,

$\beta$ - is the coefficient of heat transfer under consideration:

- $\quad$ conduction $\beta=\lambda[\mathrm{W} / \mathrm{m} \mathrm{K}]$,

- heat inflow over convection $\beta=h_{k}\left[W / m^{2} K\right]$,

- heat inflow over radiation $\beta=\mathrm{h}_{\mathrm{r}}\left[\mathrm{W} / \mathrm{m}^{2} \mathrm{~K}\right]$,

- $\quad$ or combination of these processes which is called overall heat transfer [6] $=U\left[\mathrm{~W} / \mathrm{m}^{2} \mathrm{~K}\right]$.

Inverse $1 / \beta$ of heat transfer coefficient is the heat transfer resistance put up by layers of building lining material over heat transport under consideration.

Heat flux given up from building to its surroundings is general function of energy contained in building, its insulating properties and thermal capacity distribution characteristics as well as leak tightness of the building. For practical determination the properties of building under testing it can be assumed that coefficient of proportionality of energy flux given up to surroundings vs. the energy quantity remaining in the building is constant. This coefficient describes building cooling down or heating process and energy transfer between the building and environment:

$$
\Phi=\frac{d Q}{d t}=a \cdot\left(Q^{0}-Q\right)
$$


where:

$\mathrm{Q}^{0}$ - initial heat quantity in the building [J],

$\mathrm{Q}$ - quantity of heat given up from building to surroundings [J],

$\alpha$ - constant coefficient of proportionality [1/s].

Hence the time of building thermal relaxation time $t_{r}$ (heating or cooling down) is the following:

$$
t_{r}=-\frac{1}{a} \ln \eta \quad[s]
$$

where:

$\eta$ - thermal efficiency of buildings.

As it can be expected, massive buildings with high thermal capacity have high "natural" thermal efficiency resulting in long thermal relaxation time. Together with decreasing thermal capacity of more recent designs, their thermal efficiency naturally decreases along with the time of thermal relaxation, and the importance of lining leak tightness and heat transferability is growing. Separate buildings relaxation times mutual comparing as well as comparing these times to time periods between extreme Sun irradiation of building give us information about its thermal capacity, enabling evaluation of thermal efficiency of the building.

Heat transfer resistance of building partition (wall) describes insulating-thermal properties of the partition. Described heat transfer resistance is $U$ parameter converse. This parameter is called overall heat transfer coefficient, and its acceptable values are contained in standards regarding building engineering, for example PN 91/B-2020 or DIN 4108.

The $U$ coefficient [6] is determined for accepted stationary conditions of one-dimensional heat transfer process, assuming equal density of heat flux transferred through both planes (internal and external one) limiting external wall of building. Heat flux density $q_{1}$, flowing in from inside of building through internal plane to barrier, like in Fig. 1, is equal to heat flux density qo, flowing out from barrier, through external plane of the wall, to surroundings of the building:

where:

$$
\Phi_{\circ} / A=q_{0}=q_{1}=\Phi_{1} / A
$$

$\mathrm{q}_{1}$ - heat flux density, flowing in to building wall through its internal plane is the following:

$$
q_{1}=\left(T_{1}-T_{s}\right) /\left[1 / h_{1}+1 / \Lambda\right]
$$

qo - heat flux density, transferred from building wall to surroundings through its external plane is the following (Newton equation):

$$
q_{0}=h_{0}\left(T_{S}-T_{0}\right)
$$

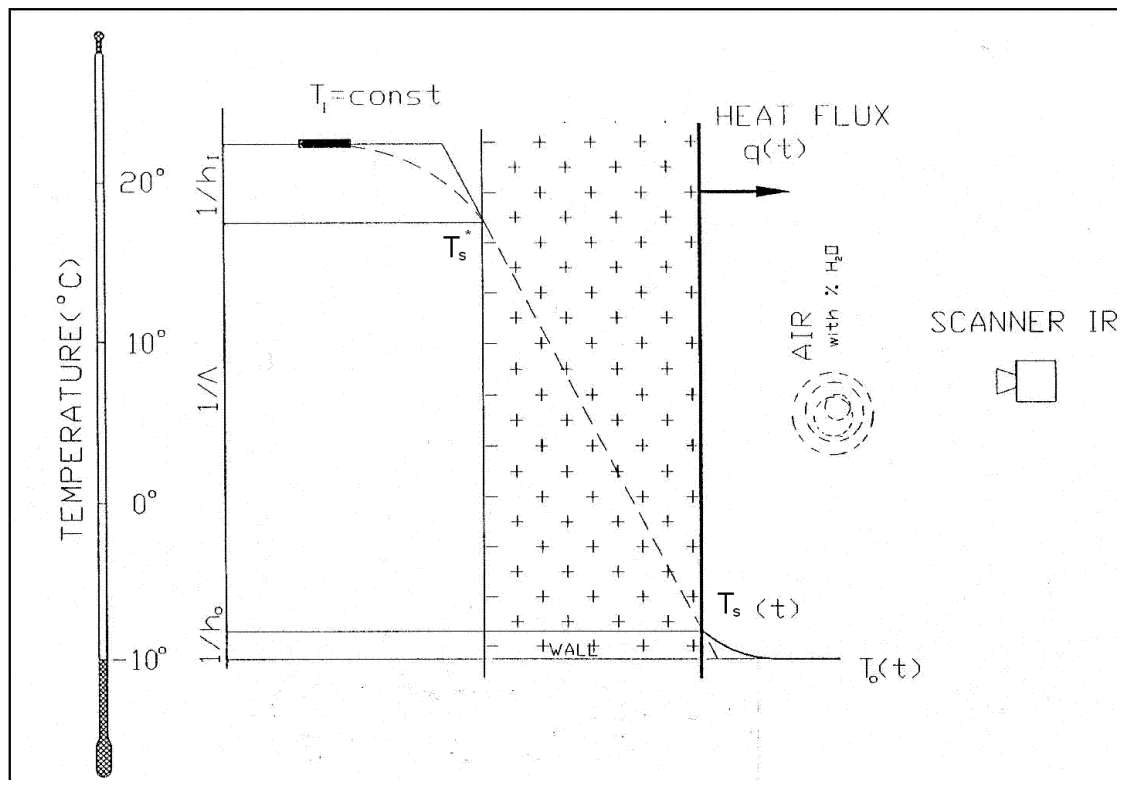

Fig. 1. Diagram of temperature variations in building barrier under stationary conditions [6]

where:

$\mathrm{T}_{1}$ - temperature inside the building $[\mathrm{K}]$,

$\mathrm{T}_{\mathrm{O}}$ - temperature of building surroundings $[\mathrm{K}]$,

$\mathrm{T}_{\mathrm{S}}$ - temperature of external face of building wall $[\mathrm{K}]$,

$\mathrm{T}_{\mathrm{S}}{ }^{*}$ - temperature of internal face of building wall $[\mathrm{K}]$, 
$h_{0}$ - coefficient of heat transfer - inflow at external face of the wall $\left[\mathrm{W} / \mathrm{m}^{2} \mathrm{~K}\right]$,

$h_{1}$ - coefficient of heat transfer - inflow at internal face of the wall $\left[\mathrm{W} / \mathrm{m}^{2} \mathrm{~K}\right]$,

$1 / \Lambda=b / \lambda$ - thermal resistance of the wall $[\mathrm{W} / \mathrm{mK}]$.

$\mathrm{b}$ - wall thickness [m].

Basing on assumption (equation 5) for heat flux inflow at the wall $q_{1}$ and its flowing out $q_{0}$ expressions we can obtain the following equation:

$$
1 / h_{1}+1 / \Lambda=\left(T_{1}-T_{S}\right) / h_{0}\left(T_{S}-T_{0}\right)
$$

Since the overall heat transfer coefficient $U$ is expressed with the following relationship:

$$
1 / U=1 / h_{0}+1 / \Lambda+1 / h_{1}
$$

then, after inserting values from equation 8 , we can obtain the following:

$$
1 / U=1 / h_{0}+\left(T_{1}-T_{s}\right) / h_{0}\left(T_{s}-T_{0}\right)
$$

and then determine the $U$ value, which describes thermal properties - insulating power of building lining walls.

$$
U=h_{0}\left(T_{S}-T_{0}\right) /\left(T_{1}-T_{0}\right)
$$

In similar way it's possible to deduce a relationship for $U$ coefficient, taking into consideration heat inflow from room inside:

$$
U=h_{1}\left(T_{1}-T^{*} s\right) /\left(T_{1}-T_{0}\right)
$$

Hence, basing on measurement of actual distribution of internal temperature in building $T_{1}$ temperature distribution on external or internal wall plane $T_{s}$ or $T_{s}{ }^{*}$ and actual distribution of temperature of external surroundings $T_{0}$, it's possible to evaluate the $U$ coefficient value. In order to determine the $U$ overall coefficient of heat transfer through the building wall, it is necessary to know values of coefficient of heat transmission by the external or internal face of the wall $h_{\circ}$ or $h_{1}$. Coefficients of heat transmission by boundary planes $h_{\circ}$ or $h_{1}$ are the sum of summands connected with air convection around boundary and summands depending on internal or external irradiation of this barrier.

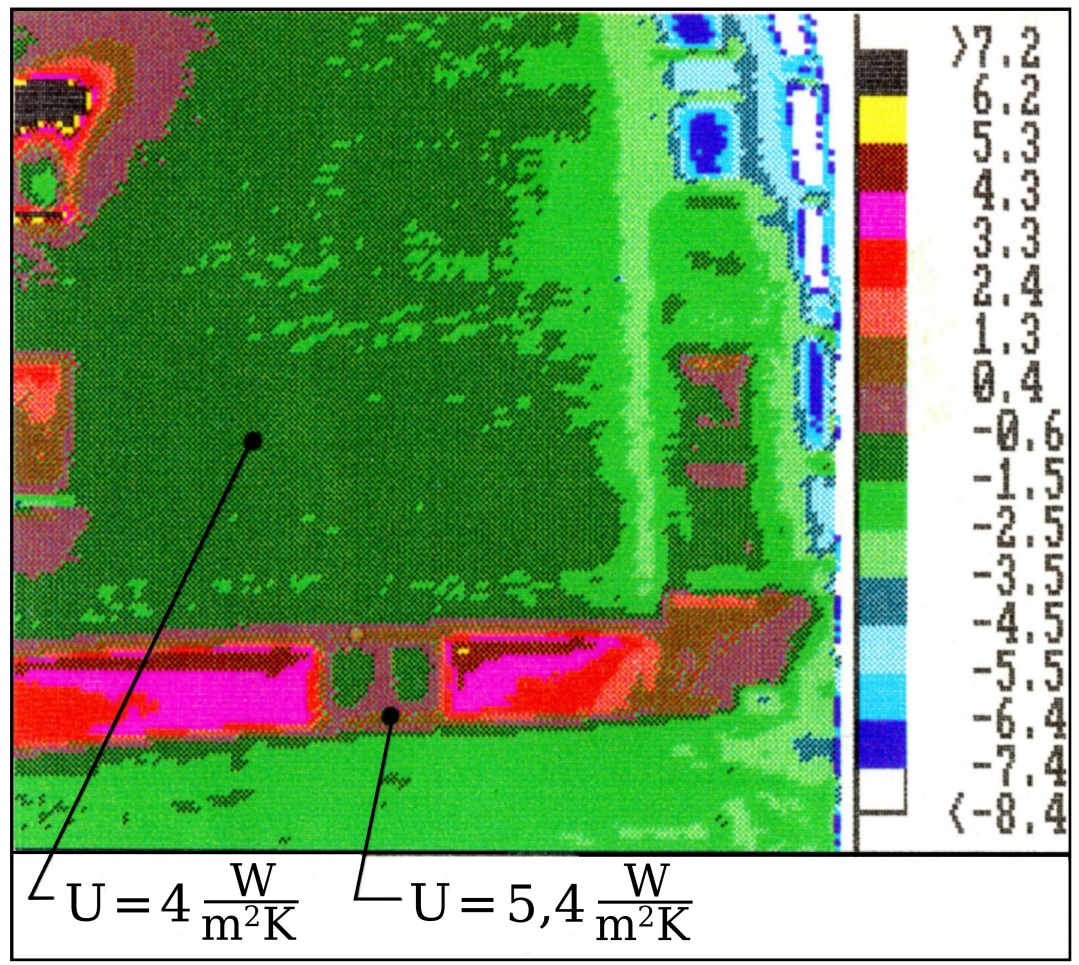

Fig. 2 Apartment building façade thermogram.

Outdoor (surroundings) temperature $T_{O}=-5^{\circ} \mathrm{C}$, indoor temperature $T_{I}=20^{\circ} \mathrm{C}$

Analysing buildings external lining thermogram the following $h_{\circ}$ values are accepted: around $14 \mathrm{~W} / \mathrm{m}^{2} \mathrm{~K}$ in windless (calm) conditions and up to $30 \mathrm{~W} / \mathrm{m}^{2} \mathrm{~K}$ in case of blowing wind. For internal thermograms, values $h_{1}$ are accordingly from $7,8 \mathrm{~W} / \mathrm{m}^{2} \mathrm{~K}$ to $11,4 \mathrm{~W} / \mathrm{m}^{2} \mathrm{~K}$.

Considering overall heat transfer coefficient $U$ value, evaluated in above way, it's necessary to tell distinctly that overall heat transfer coefficient $U$ value alone, determined for heat transport, is very disputable both in its meaning and with respect to its measurement. It's arising due to fact that assumption regarding heat flux density flowing out from the barrier to surroundings that is constantly equal to density of heat flux transferred into the barrier, accepted during defining such value, is fulfilled in fact only by barriers without heat capacity or, what is the same, by very thin ones. In the light of such assumption, the heat capacity problem is negligible but it is never true in reality. Neglecting barrier heat capacity reduces real thermal dynamics problem of the barrier to the static 
(stationary) one. The barrier, in fact, is under continuous process of cooling down and heating that is called thermal keeping up with surroundings. On the other hand, the overall heat transfer coefficient $U$ value can by no means be the one characterising thermal insulating properties of barrier. It is that because the coefficient describes exclusively the temperature intensity (rate) of hypothetical heat flux density that would be transferred through barrier under stationary conditions (invariable with time). Since buildings are continuously exposed to thermal influence of surroundings, such conditions never occur in reality. Such continuous influence is the reason that there is no real way to establish initial conditions for theoretical issue of thermal conduction in barrier, described by Fourier equation.

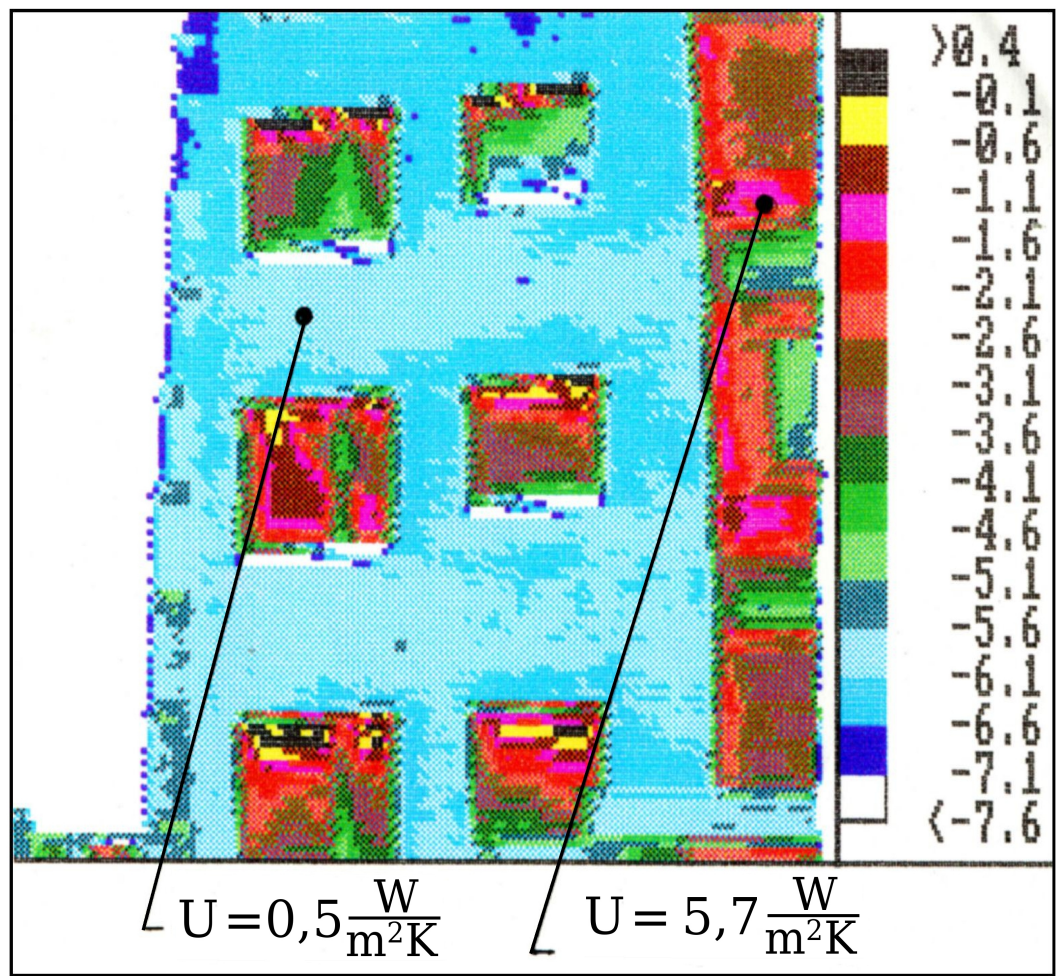

Fig.3 Multi-family apartment building façade thermogram.

Outdoor(surroundings) temperature $T_{O}=-4,5^{\circ} \mathrm{C}$, indoor temperature $T_{I}=20^{\circ} \mathrm{C}$

Despite above reservations, overall heat transfer coefficient $U$ value is accepted as standard that is mandatory for determination the thermal-insulating properties of building lining.

\section{Thermal imaging equation. Assumption and necessary condition.}

According to above description, in order to determine the distribution of building insulation thermal resistance value it is necessary to know the distribution of actual - current value of object walls temperature. At the same time it should be emphasised that knowing only the distribution of current temperature of surface of building under testing does not give information about the quantity of heat being transferred through this surface.

Distribution of actual temperature of wall surface or all the building lining should be determined by radiometric method [4], using its main feature - contact less measurement of any surface temperature in real time. Such capability makes the thermography very sophisticated and efficient measurement tool.

However, in building engineering, such remote measurement of temperature distribution on internal and external surfaces of any building barrier is more uncertain, burdened with possibility to make considerable error and demanding use of radiometers with sufficient sensitivity. The reason is small thermal contrast between these surfaces and surroundings. Due to relatively small temperature differences between building surfaces and surroundings, thermographic testing of modern buildings in surroundings needs to use the equipment with sufficient sensibility and at proper spectral range. Narrow range of environment temperature variability has to be measured with radiometer at sufficiently fine division of this range by the device. At thermography of building, user of the device has to be familiarized not only with principles of radiometric measurement exclusively the object's own emission, like in most industrial thermography applications, but also be capable of measuring with radiometer the $\mathrm{B}$ object brightness in scene [7], considering the building irradiance $\mathrm{E}_{0}$ by surroundings in test results. Hence, the misunderstandings appear regarding recognizing radiometric method as reliable, quantitative method for building thermal efficiency determination.

In fact, in every thermographic testing of buildings in environment, the brightness B of tested object is determined in its thermal scene. 
Basic equation [3] of thermal imaging of the building in surroundings, what means the object in thermal scene, results from heat radiation budget over surface being imaged and is the equation of radiance $L$ in this scene in the form of second order Fredholm integral equation.

$$
L(x)=\Lambda_{e}(x)+\int_{\Omega} L(y) \rho(x, y) d y
$$

where:

$\Lambda_{\mathrm{e}}(\mathrm{x})$ - object's own thermal emission at the point $\mathrm{x}$,

$\Omega$ - unit hemisphere over $\mathrm{x}$ point as a limit of integration.

Formal solution of this equation can be presented in the following form:

$$
L=\Lambda_{e}+\mathfrak{R} L
$$

where $\Re$ is the integral operator of radiation transport in scene and radiance $L$ can be presented with Neumann series:

$$
L=[I-\Re]^{-1} \Lambda_{e}=\sum_{n=0}^{\infty}(\Re)^{n} \Lambda_{e}
$$

Every term of above series is the effect of own thermal emission from all surfaces of the scene. Amount of energy reflected from all scene surfaces doesn't exceed the emitted energy. This is the condition for Neumann series convergence and results from principle of conservation of energy. In case of considering not only the energy of radiance $L$ [3] but amount of energy emitted from unit area to unit sphere above considered point, then the following terms are used: brightness $B_{T}$, emission - emittance $M$ and irradiance $E_{0}$ from surroundings.

$$
B_{T}(x)=M(x)-E_{O}(x)
$$

Emittance $M(x)$ of point $x$ of the wall is the sum of the following elements of radiation: own thermal emission-emittance $M_{e}(x)=\varepsilon \sigma T^{4}$ of $x$ point of the wall and reflected from this point irradiance $E_{o}(x)$ from surroundings.

$$
M(x)=M_{e}(x)+\rho_{d}(x)+E_{o}(x)
$$

Hence, the object brightness $B_{T}$ can be expressed by the following equation:

$$
B_{T}(x)=M_{e}(x)-\rho_{d}(x)+E_{O}(x)
$$

The following thermal radiation emission distributions and their appropriate weight coefficients appear in above equations:

- $\quad \mathrm{B}_{\mathrm{T}}$ - brightness of target point $\mathrm{x}$ of building wall,

- $\quad M$ - emission-emittance from point $x$ of building wall,

- $\mathrm{M}_{\mathrm{e}}(\mathrm{x})=\varepsilon \sigma \mathrm{T}^{4}$ - own thermal emission-emittance from point $\mathrm{x}$ of building wall,

- $E_{0}$ - irradiance from surroundings at the point $x$ of building wall,

- $\quad \rho_{\mathrm{d}}$ - diffusive reflectance at point $x$ of building wall,

- $\varepsilon$ - total hemispherical emissivity at point $x$ of building wall.

Above equation (18) of imaging surface in thermal scene results from deliberations on thermal radiation balance over imaged surface and describes density of net emitted energy from object to surroundings. The equation was derived at assumption that scene is filled with diathermic medium [1] and objects in the scene are opaque. The equation of thermal imaging of objects in surroundings can have an alternative form:

$$
\Delta \mathrm{q}=\varepsilon_{\mathrm{T}}\left[\sigma \mathrm{T}^{4}-\sum_{\mathrm{i}} \mathrm{B}_{\mathrm{io}}\left(\mathrm{T}_{\mathrm{oi}}\right) \mathrm{F}_{\mathrm{i}-\mathrm{T}}\right]
$$

where:

1. $\Delta q$ - net quantity of heat emitted from object to surroundings. This quantity causes reaction of detector placed in the scene,

2. $\varepsilon$ - total hemispherical emissivity at point $\mathrm{x}$ of building wall.

3. $\sigma$ - Stefan constant,

4. $\varepsilon_{\top} \sigma T$ - own thermal emission-emittance from point $x$ of building $M_{e}$ wall, with wall temperature $T$,

5. $\sum_{i} B_{i o}\left(T_{o i}\right) F_{i-T}$ - sum of irradiances from "i" surfaces of surrounding in temperatures $T_{0 i}$ emitting at imaged building surface. Total irradiance is expressed by weight coefficient $F_{i-T}$ (configuration coefficient) that determines what part of energy emitted from "i" surface of surroundings at imaged surface of building.

In standard radiometric testing [8] of object temperature it's assumed that two-dimensional distribution of emission from objects that constitute surroundings of object under testing which means that irradiance $E_{0}$ from surroundings is equal to constant distribution of black radiation emission, emitted by black body (ideal radiator) at surroundings temperature $T_{\mathrm{O}}$.

$$
E_{O}=\sum_{i} B_{i o}\left(T_{0 i}\right) F_{i-T} \approx \sigma T_{0}^{4}
$$

This is fundamental, highly simplifying, assumption of measuring thermography at radiometric measurement of objects temperature in thermal scene.

In standard radiometric measurements, it's furthermore assumed that equality of irradiance $E_{O}$ from surroundings at building being imaged and irradiance of surroundings $E_{D}$ at imaging detector.

$$
\mathrm{E}_{\mathrm{D}}=\mathrm{E}_{\mathrm{O}}
$$

This is necessary condition of radiometric testing correctness, led in specific environment. Fulfilling such condition causes fulfilling necessary equality of true object surface brightness and emittance from object being 
imaged that incidence on detector measured by it is equal. This equality happens in measurement situation when object and detector are in the same environment.

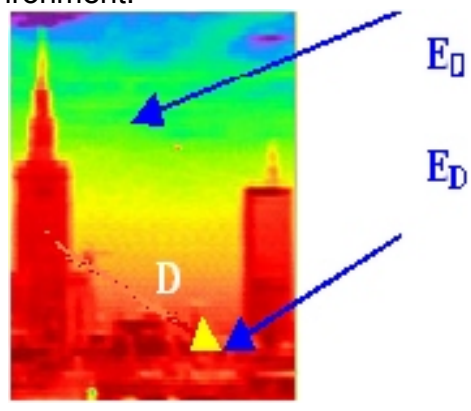

Fig.4 Irradiance $E_{O}$ at object from surroundings under testing has to be equal to irradiance $E_{D}$ at detector from surroundings .

\section{Efficiency and heat transfer of building walls in true conditions of surroundings}

Internal climate parameters of building have to be maintained at the level close to thermal comfort parameters. It can be done thanks to energy from outside of building. The energy being supplied is turned in the building into heat $Q^{0}$, of which the part $Q$ is dissipated to surroundings and the second part $Q^{0}-Q$ causes increasing or, if any, decreasing the internal climate parameters, approaching the climate values to thermal comfort ones in this building. Such division of supplied heat $Q^{0}$ into $Q$ and $Q^{0}-Q$ is pure abstract division of initial quantity of heat $\mathrm{Q}^{0}$.

Thermodynamic term of device efficiency [2] relates to such heat quantity that effectively turns into work in this device. In the building, useful heat $Q^{0}-Q$ is used to internal climate regulation in such way that buildings accomplish their protective function. The function $\eta$, called thermal efficiency of building, is taken and it has the following form:

$$
\eta=\frac{Q^{\circ}-Q}{Q^{\circ}}
$$

Such function enables to characterise energetic properties of considered building. Instead of thermal efficiency of building $\eta$ it's possible to enter the expression describing the heat "inefficiency" $\theta$ as shown in the following:

$$
\theta=\frac{Q}{Q_{0}}=1-\eta
$$

Such "inefficiency", accordingly to described by it lining property, could be called "permeability" of heat from the building.

Examination of values of expressions $\eta(T)$ and $\theta(T)$, recognised as temperature $T$ functions in surroundings of imaged points on internal surfaces, lining and external environment of building, can be more effective way to determine insulation properties of building lining than to determine the overall heat transfer coefficient $U$ that is not the best value characterising thermal properties of barriers in buildings. Assuming again the following values:

1. initial heat supplied to the object - amount energy in relation to surroundings $-Q^{0}[\mathrm{~J}]$,

2. heat escaping from object to surroundings $-Q[\mathrm{~J}]$,

3. heat remaining in the object and used in building $=Q^{0}-Q[J]$,

4. thermal sensitivity of radiometer [4] NEP [W] $1[\mathrm{~s}]>>\delta Q^{0}[\mathrm{~J}]$ must be significantly higher than some quantity $\delta>0$ of heat initially contained in the object

and then we can perform the following discussion on imaging conditions, however, two extreme cases exhibiting in the background of surroundings of this object can appear:

- If $Q<\delta Q^{0}$ then $Q / Q^{0}<\delta$. In such case, the heat escaping object is smaller than device sensitivity. In such situation the object is totally invisible in the background of surroundings and it's impossible to differentiate between it and surroundings.

- If $Q^{0}-Q<\delta Q^{0}$ then $Q / Q^{0}>1-\delta$. In such case, the heat escaping object is significantly bigger than device sensitivity. In such situation thermal image of whole object is in strong contrast with surroundings what means that temperature of whole object is much higher than surroundings one.

Measurement situation is presented in figure 5. Main measurement parameter is surroundings temperature $T_{0}$, which is the reference level for energy measurement. Moreover, according to previous point of the work, temperature inside building $T_{1}$, temperature of external surface of the wall $T_{S}$ or temperature of internal surface of the wall $T_{s}{ }_{s}^{*}$ define the process of heat transfer. Considering the two above extreme cases of heat escape to surroundings it's plain that proper thermal imaging is performed when the scanner sensitivity $\delta$ for given object at specific surrounding temperature would be in the following range:

$$
\delta<Q / Q^{0}<1-\delta
$$




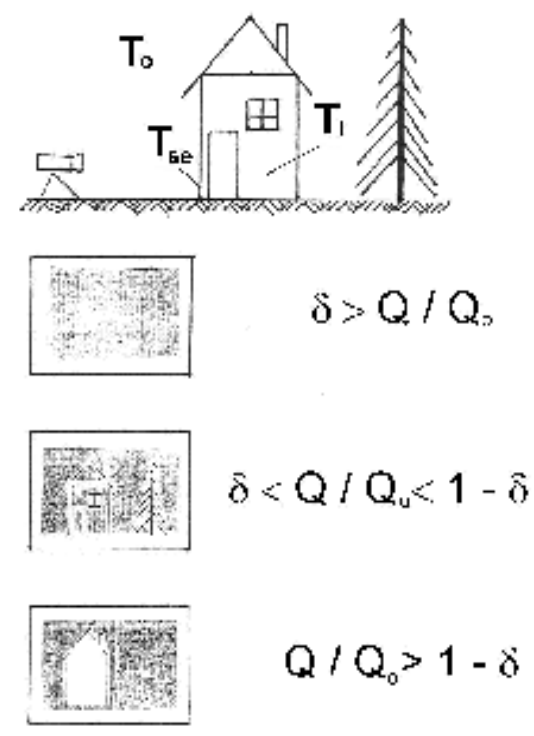

Fig. 5 Values of scanner range $\delta$ measurement temperatures and effect of their selection on performed thermograms

But, at the same time, the $Q / Q^{0}$ value describes the heat permeability $\theta$ of given object at given surrounding temperature $T_{0}$. Hence, it can be deduced that permeability $\theta$ or connected heat efficiency of building $\eta$ at given surrounding temperature $T_{0}$, determines thermographic device sensitivity range $\delta$ to perform correct building imaging at given surrounding temperature $\mathrm{T}_{0}$. Above conclusion can be reversed. Taken scanner sensitivity range $\delta$ determines the degree of accuracy of determination of heat permeability $\theta$ of selected object at given surrounding temperature $\mathrm{T}_{0}$.

Taking that heat quantities $Q$ and $Q^{0}$ have form of continuous temperature functions and have derivatives at least of first order, the functions can be deployed into the Taylor series an hence, in case of heat $Q$ escaping from building, can get the following form:

$$
Q=Q\left(T_{S}\right)-Q\left(T_{O}\right)=Q\left(T_{O}+\Delta T\right)-\left.Q\left(T_{O}\right) \cong \frac{\partial Q\left(T_{O}\right)}{\partial T}\right|_{T=T_{O}} \cdot\left(T_{S}-T_{O}\right)
$$

and in case of heat $\mathrm{Q}^{0}$ initially contained in building, can get the following form:

$$
Q^{0}=Q^{0}\left(T_{I}\right)-Q^{0}\left(T_{O}\right)=Q^{0}\left(T_{O}+\Delta T\right)-\left.Q^{0}\left(T_{O}\right) \cong \frac{\partial Q^{0}\left(T_{O}\right)}{\partial T}\right|_{T=T_{O}} \cdot\left(T_{I}-T_{O}\right)
$$

Hence, after inserting the values from equation 25 and 26 to equation 24 we get important relationship between factor,$\delta$ determining scanner sensitivity and temperatures of building surface $T_{1}$, $T_{S}$ and surrounding $T_{0}$.

$$
\delta \leq \gamma \frac{T_{S}-T_{O}}{T_{I}-T_{O}} \leq 1-\delta
$$

where:

$\gamma$ is the numerical factor derived from ratio of derivatives of heat function $Q$ and $Q^{0}$ of equation 25 and 26 at temperature equal to surrounding temperature $T_{0}$, after inserting $Q$ and $Q^{0}$ to relationship 24 .

From above considerations also goes the following relationship that connect overall heat transfer coefficient $U$ (equation 11 and 12) with thermal permeability $\theta$ of building (equation 23) and corresponding building thermal efficiency $\eta$ (equation 22). From equation for $Q$ and $Q^{0}$ values determined by relationships 25 and 26 , from equation 11 , we get the following relationship:

$$
U=h_{\circ} \theta=h_{\circ}(1-\eta)
$$

at the same time $h_{\circ}$ is coefficient of heat transfer - inflow on external surface of wall and building thermal efficiency $\eta$ results from equation 23 and it can be presented as the following relationship:

$$
\eta=\frac{T_{I}-T_{S}}{T_{I}-T_{O}}
$$

where:

$\mathrm{T}_{1}$ - temperature of building lining inside behind imaged wall,

$\mathrm{T}_{\mathrm{s}}$ - temperature of external plane of imaged lining wall,

$\mathrm{T}_{\mathrm{o}}$ - outdoor (surroundings) temperature.

Like in relationship 29 , thermal permeability $\theta$ of the wall is the following: 


$$
\theta=\frac{T_{S}-T_{O}}{T_{I}-T_{O}}
$$

Similarly to relationship 11 , in which the coefficient ho of heat transfer - inflow on external surface of wall is used, it is possible to use dependence of overall heat transfer coefficient $U$ on $h_{\text {l }}$ of heat transfer - inflow on internal surface of wall (see equation 12):

$$
U=h_{1} \theta=h_{1}(1-\eta)
$$

at the same time $h_{1}$ is the coefficient of heat transfer - inflow on internal surface of wall. But in this case, the values of thermal permeability $\theta$ of the wall are determined in somewhat another way:

$$
\theta=\frac{T_{I}-T_{S}^{\bullet}}{T_{I}-T_{O}}
$$

and wall thermal efficiency $\eta$ :

$$
\eta=\frac{T_{S}^{\bullet}-T_{O}}{T_{I}-T_{O}}
$$

where:

$T_{1}$ - temperature of building lining inside behind imaged wall,

$\mathrm{T}^{\cdot} \mathrm{S}$ - temperature of internal plane of imaged lining wall,

To - outer temperature.

When the inequality 24 is satisfied, thermogram is temperature diverse and imaged building contrasts with surrounding. In thermal scanner AGEMA 880 LWB, which is capable to record temperatures from $-20{ }^{\circ} \mathrm{C}$ to +200 ${ }^{\circ} \mathrm{C}$, there are the following sensitivity subranges $\delta-0,4 \%, 1 \%, 2 \%, 4 \%, 10 \%, 20 \%, 40 \%, 100 \%$ of full measured temperatures range equal to $220^{\circ} \mathrm{C}$. This full range corresponds to 500 symbolic units, called isothermal values. Yet in year 2000, for buildings of good insulating power, tests were performed with sensitivity $0,4-2 \%$, enabling temperature differences determination at the level of $0,88{ }^{\circ} \mathrm{C}-4,4{ }^{\circ} \mathrm{C}$. In case of buildings of medium insulating power, used sensitivity was $4 \%$, enabling maximum temperature difference determination up to $8,8{ }^{\circ} \mathrm{C}$ and in case of building of insufficient insulating power, used sensitivities were $10 \%-40 \%$, enabling temperature difference determination in the range of $22{ }^{\circ} \mathrm{C}-88{ }^{\circ} \mathrm{C}$. In the latter range, relative temperature difference span $\left(T_{s}-T_{0}\right.$ ) between imaged surface of building wall and its surroundings is as much as 200 isothermal values (40\% of range), covering possible range of temperature difference $\left(T_{1}-T_{0}\right)$ between building inside and its surroundings that was, as an example, $40{ }^{\circ} \mathrm{C}$. Basing on this we estimate that presented on thermogram temperature difference $\left(T_{s}-T_{0}\right)$ between wall surface of imaged building and surroundings is $16{ }^{\circ} \mathrm{C}$. This is, of course, highly exaggerated value, resulting in value of overallheat transfer coefficient of around $U=$ $5,6 \mathrm{~W} / \mathrm{m}^{2} \mathrm{~K}$ at $\mathrm{h}_{0}=14 \mathrm{~W} / \mathrm{m}^{2} \mathrm{~K}$.

Polish buildings 1995

$$
\begin{aligned}
0,005 \leq & \frac{T_{S}^{*} T_{O}}{T_{I}-T_{O}} \leq 0,025 \\
& \frac{T_{S}-T_{O}}{T_{I}-T_{O}} \approx 0,05 \\
0,1 \leq & \frac{T_{S}^{*}-T_{O}}{T_{I}-T_{O}} \leq 0,4
\end{aligned}
$$

Buildings with very good insulation

Buildings passed

Buildings with bad insulation, requiring improvement insulation

Polish buildings 2005

$$
\begin{array}{r}
0,004 \leq \frac{T_{S}^{*}-T_{O}}{T_{I}-T_{O}} \leq 0,01 \\
\\
\frac{T_{S}^{*}-T_{O}}{T_{I}-T_{O}} \square 0,02 \\
0,04 \leq \frac{T_{S}-T_{O}}{T_{I}-T_{O}} \leq 0,1
\end{array}
$$

Buildings with very good insulation

Buildings currently passed

Buildings with bad insulation, requiring improvement insulation

But currently, the limits have changed, so testing buildings of good insulation power sensitivities $0,4-1 \%$ are used, enabling temperature difference determination in the range of $0,88^{\circ} \mathrm{C}-2,2{ }^{\circ} \mathrm{C}$. In case of buildings of medium insulation power the used sensitivity was $2 \%$, enabling determination of maximum temperature 
difference up to $4,4{ }^{\circ} \mathrm{C}$ and in case of building of insufficient insulating power, used sensitivities were $4 \%-10 \%$, enabling temperature difference determination in the range of $8,8^{\circ} \mathrm{C}-22{ }^{\circ} \mathrm{C}$. In the latter range of sensitivity, relative temperature difference span $\left(T_{S}-T_{0}\right)$ between imaged surface of building wall and its surroundings is 50 isothermal values (10\% of range), covering possible range of temperature difference $\left(T_{1}-T_{0}\right)$ between building inside and its surroundings that was, as an example, $40{ }^{\circ} \mathrm{C}$. Basing on this, estimated on thermogram maximum temperature difference $\left(T_{s}-T_{0}\right)$ between wall surface of imaged building and surroundings is $4{ }^{\circ} \mathrm{C}$. This is more real (true) value, bringing the overall heat transfer coefficient value of around $U=1,4 \mathrm{~W} / \mathrm{m}^{2} \mathrm{~K}$ at $h_{0}=14 \mathrm{~W} / \mathrm{m}^{2} \mathrm{~K}$ or $3,0 \mathrm{~W} / \mathrm{m}^{2} \mathrm{~K}$ at $\mathrm{h}_{0}=30 \mathrm{~W} / \mathrm{m}^{2} \mathrm{~K}$ in conditions of blowing wind.

Implementing values of thermal permeability $\theta$ or thermal efficiency $\eta$ into the thermal testing of buildings and using additionally some normalization of these values, for example at internal temperature $\mathrm{T}_{1}=20^{\circ} \mathrm{C}$ as well as two external temperatures $\mathrm{T}_{0}=5{ }^{\circ} \mathrm{C}$ and $\mathrm{T}_{0}=-5{ }^{\circ} \mathrm{C}$, it would be possible to obtain simple comparative indicator of assessment of thermal behaviour of buildings under testing.

It can be suggested (figure 6) demonstration thermogram of building with standard (in 2007) thermal efficiency $\eta$ contained in the range of $0,966<\eta<0,942$. Higher efficiencies are currently practically unavailable. Temperature distribution of imaged surface of building façade is balanced even with temperature of windows existing in this façade. Masured wall temperature is only little higher than surroundings one which, in this case, is temperature of the roof over attic without heating (blue colour).

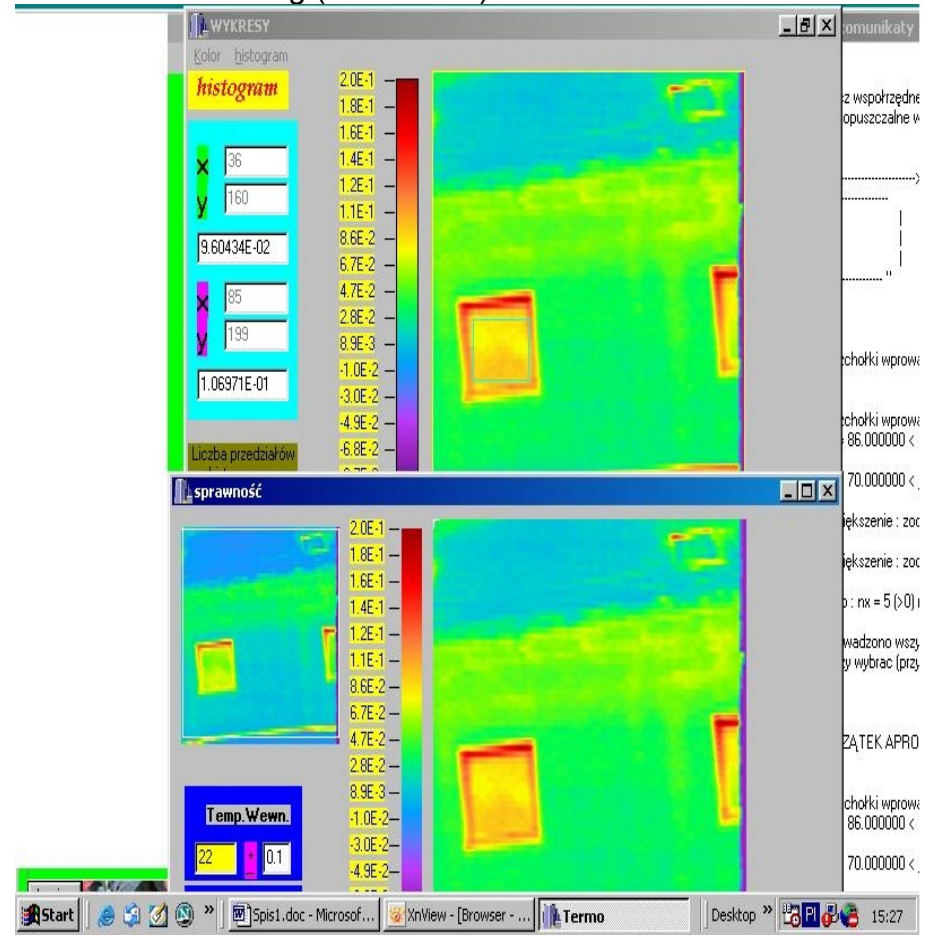

Fig.6 Thermogram of building wall with higher as posible thermal performance $\eta$ in real conditions In this case building thermal efficiency is $0,996<\eta<0,942$

\section{Conclusions}

1. Heat dissipation from building to surroundings depends on this surroundings and its variable conditions, three-dimensional distribution of building lining thermal resistance, thermal capacity and tightness. This causes the radiometric method basing on detection of distribution of thermal radiation intensity from any object in real time should be absolutely used for testing the course of process of heat dissipation from buildings.

2. Radiometric equipment, sensitive in range $8-14 \mu \mathrm{m}$ of radiation wavelengths can be used in building thermography provided that it has sufficiently high sensitivity (thermal resolution NETD $\approx$ $0,05 \mathrm{~K}$ at $273,15 \mathrm{~K}$ ). Radiometers for such testing should be distinguished by narrow temperature measurement range, for example $253 \mathrm{~K}$ - $373 \mathrm{~K}$. The temperature measurement range of such radiometer should cover environment temperatures, with simultaneously, possible dense division of the range into operating subranges.

3. Meaning of formal condition in standard thermographic building testing which is related to minimum temperature gradient in imaged building wall, between building inside and its surroundings $\mathrm{T}_{1}-\mathrm{T}_{\mathrm{O}} \geq 15^{\circ} \mathrm{C}$, will be decreasing along with development of detector technology and improvement of their sensitivity. 
4. In comparison to industrial thermographic imaging, the brightness B of modern buildings in surroundings is very small hence, it is necessary to test very carefully surroundings irradiance $E_{O}$ on imaged building.

5. Base measurement thermography assumption that distribution of surroundings irradiance $E_{O}$ is equal to constant emission distribution of balanced radiation of black body of surroundings temperature $T_{0}$ have to be examined in detail during every thermal imaging of building.

6. In thermal building imaging in conditions of overcast, the temperature of soil surrounding the building surface can be accepted as surroundings temperature. In case of clear sky, the soil temperature can be accepted as surroundings one but only in thermal imaging of wall in low building. In conditions of no clouds, all buildings roof as well as tall buildings wall are irradiated by the sky with temperature $\approx 220 \mathrm{~K}$.

7. Radiometric measurement of distribution of current object surface temperature, being in radiating surroundings, is made with at least the same uncertainty as surroundings temperature measurement one. If such surroundings temperature measurements is not performed during thermographic building examination then absolute values of temperature and its distribution on thermogram are not properly determined and such measurement results uncertainty is enormous and such radiometric examination is worthless. However, temperature differences occurring in various points of imaged surface, are well assessed in relation to accepted temperature measurement range, even in case of high uncertainty of surroundings temperature measurement.

8. Changes in emissivity values of surface influence the temperature measured by radiometric mode inverse proportionally to temperature distribution differentiation in scene. More differentiated temperature distribution in scene more influence of surface emissivity changes on values of temperature measured by radiometric mode. More the temperature distribution in scene balances, the changes of scene surface emissivity less influence on values of such scene surface temperature measured by radiometric mode.

9. True heat transfer $\theta$ or connected with it building thermal efficiency $\eta$ at given surroundings temperature $T_{0}$, describes range of changeability of thermographic equipment sensitivity $\delta$ choice for proper thermal imaging of the object, so its thermal image would be differentiated by temperature at specific surroundings temperature $\mathrm{T}_{\mathrm{O}}$.

10. Accepted sensitivity $\delta$ of scanner describes range of changeability of heat transferability $\theta$ determination or connected with it thermal efficiency $\eta$ of given building at given surroundings temperature $T_{0}$.

11. In current technical conditions of workmanship realization, Polish buildings should demonstrate planned heat transferability of lining in the range $0,4 \%<\theta<4 \%$, so the overall heat transfer coefficient should be within the limits of $0,05 \mathrm{~W} / \mathrm{m}^{2} \mathrm{~K}<\mathrm{U}<0,46 \mathrm{~W} / \mathrm{m}^{2} \mathrm{~K}$, with accepting the average value of coefficient of heat transfer inflow on external wall is $h_{\circ}=11,4 \mathrm{~W} / \mathrm{m}^{2} \mathrm{~K}$.

12. Standard thermogram (fig. 6) of building describes the range of thermal transferability $\theta$ from this imaged standard building at the level $3,4 \%<\theta<5,8 \%$ what causes the overall heat transfer coefficient $U$ for this building, at accepted minimum value of coefficient of heat inflow on external wall is $h_{\circ}=7 \mathrm{~W} / \mathrm{m}^{2} \mathrm{~K}$, changes within the limits of $0,2 \mathrm{~W} / \mathrm{m}^{2} \mathrm{~K}<\mathrm{U}<0,4 \mathrm{~W} / \mathrm{m}^{2} \mathrm{~K}$.

\section{REFERENCES}

[1] M. Planck. The theory of heat radiation. Dover Publications (1959).

[2] E. Fermi. Thermodynamics. Prentice-Hall Inc. (1937)

[3] P., H. Moon, D., S. Spencer. The fotic field. The MIT Press (1981).

[4] G., C. Holst. Common sense approach to the thermal imaging. SPIE Optical Engineering Press (2000).

[5] B. Pettersson, B. Axen. Thermography. Testing of the thermal insulation and airtightness of buildings. Swedish Council for Building Research. (1980).

[6] J. Jaworski. Termografia budynków. Dolno-śląskie Wydawnictwo Edukacyjne (2000).

[7] E. Kostowski. Promieniowanie cieplne. Państwowe Wydawnictwo Naukowe (1993)

[8] ASHRAE 101 - 1981, ISO 6781 - 1983, ASTM C1060 - 1987, NIST Special Publication (SP) 2501998, 